\begin{tabular}{|l|}
\hline 102 - 103 \\
Debate \\
e Investigación \\
La gestión del patrimonio \\
arqueológico en las \\
comunidades autónomas: \\
balance y situación actual \\
PH48 - Abril 2004 \\
\hline
\end{tabular}

queológicas anuales, prácticamente todas ellas de carácter preventivo. Porque ese es otro cambio importante: después del aumento espectacular que sufrieron en los 80 las Ilamadas "urgencias", las gestoras y gestores del Patrimonio Arqueológico han conseguido que tal concepto vaya siendo sustituido por el de "preventivas", refiriéndose estas a las intervenciones que, aún siendo motivadas por una obra pública o privada, se ajustan a un proyecto aprobado por la administración competente.

En este trabajo vamos a centrarnos en el análisis de algunos de los nuevos mecanismos de protección que se han creado y que aparecen en la normativa, así como en sus consecuencias más significativas.

El hecho de que los bienes arqueológicos, en buena parte, se sitúen bajo el suelo, provoca que las medidas de protección que necesita no sean las mismas que las que resulten efectivas sobre unos bienes visibles; además de orientarse más evidentemente hacia la prevención, han de estar ligadas al ordenamiento de los territorios y a las previsiones tomadas antes de cualquier obra. Así se han ido tejiendo, poco a poco en número creciente, toda una serie de medidas y figuras de protección que no estaban contempladas en la Ley de Patrimonio Histórico Español de 1985.

Muchas de estas medidas surgen de ideas que habian sido ya expresadas en documentos internacionales, sobre todo en el "Convenio Europeo para la protección del Patrimonio Arqueológico (Londres 1969)" del Consejo de Europa (al que España se adhiere en 1975) o su revisión más reciente "Convención Europea para la protección del Patrimonio Arqueológico (La Valetta, 1992)" al que España aún no se ha adherido. Además han influido otros documentos relacionados con la Arqueología Urbana, el Patrimonio Industrial, la Arqueología Subacuática o el uso de Detectores de Metales.

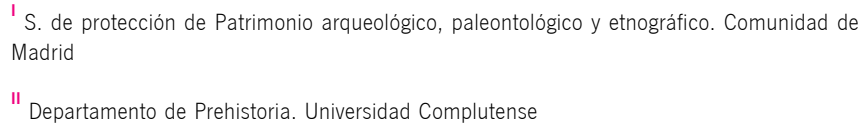

Las principales novedades que se expresaban en estos documentos y que, con mayor o menor fortuna, se han intentado reflejar en nuestra normativa, son:

$>$ la conveniencia de reservar yacimientos, o parte de ellos, sin excavar para el futuro.

> la preocupación por la calificación profesional de arqueólogas y arqueólogos, preocupación que en nuestro país es mayor ante la ausencia de una titulación universitaria en Arqueología.

> la acción educativa formal y no formal, para desarrollar el respeto por los restos del pasado.

> la elaboración de inventarios y su inclusión en las políticas de planeamiento territorial, de ocupación de los suelos, de agricultura, de medio ambiente, etc.

$>$ la adecuada conservación de los bienes obtenidos en las intervenciones, preferentemente en su lugar original.

$>$ la accesibilidad del público al Patrimonio Arqueológico

Desde unos mecanismos comunes de protección, expresados en la Ley de Patrimonio Histórico Español, se contemplan tratamientos particularizados según la naturaleza de los bienes -mueble o inmueble -, su relevancia -mayor o menor- y su consideración -artístico, etnológico, monumental, documental, entre otros -. De entre ellos, el arqueológico se caracteriza, según las leyes de Patrimonio Histórico o Cultural, por:

$>$ la susceptibilidad o la necesidad de ser estudiado con una metodología específica, la arqueológica, junto a su carácter histórico. $>$ ser bienes de dominio público. Se caracterizan éstos por estar excluidos del tráfico jurídico privado, exclusión que tiene como principal finalidad la de asegurar el uso público de esos bienes, lo que no resulta incompatible con la existencia sobre ellos de una propiedad privada.

> su fragilidad, ya que la mayoría de sus bienes no se ven, están enterrados a mayor o menor profundidad, por lo que cualquier movi-

\title{
Voces
}

\section{La ilegalidad del Proyecto de Restauración y Rehabilitación del Teatro Romano de Sagunto}

Concepción Barrero Rodríguez > Eduardo Caruz Arcos Profesores de Derecho Administrativo, Universidad de Sevilla

\section{Antecedentes}

Un ciudadano - en ejercicio de la acción pública reconocida por el art. 8.2 de la Ley 16/ 1.986, de 25 de junio, del Patrimonio Histórico Español (en adelante LPHE)- impugnó ante la Sala de lo Contencioso-Administrativo del Tribunal Superior de Justicia de Valencia la resolución de la Dirección General de Patrimonio Artístico de la Consejería de Cultura, Educación y Ciencia de la Generalidad Valenciana por la que se aprobó el "Proyecto de Restauración y Reha- bilitación del Teatro Romano de Sagunto". El recurso fue estimado por Sentencia de 30 de abril de 1993 que anula el Proyecto en cuestión dejándolo sin efecto, pronunciamiento que fue recurrido en casación tanto por la Comunidad Autónoma de Valencia como por el propio Ayuntamiento Saguntino. La Sentencia de la Sala Tercera del Tribunal Supremo de 16 de octubre de 2.000 - de la que fue ponente D. Manuel Campos Sánchez-Bordona- desestimó el recurso de casación y confirmó la legalidad de la sentencia de instancia.

La Sentencia del Tribunal Superior de Justicia de Valencia examina la compatibilidad del proyecto aprobado con lo dispuesto para las operaciones de intervención en bienes históricos por el artículo 39.2 de la LPHE. Señala, en su interpretación de este precepto, que "la ley claramente establece un límite de tipo positivo: que las intervenciones en los inmuebles vayan dirigidas a su conservación, consolidación y rehabilitación; y otro negativo: evitar la reconstrucción", límite que tiene, no obstante, "su excepción, la de que se utilicen partes originales de los mismos y 


\begin{tabular}{|c|c|c|c|}
\hline & Sin declaración & Nivel medio & Nivel máximo \\
\hline Ley $16 / 85$ del PH Español & Bienes integrantes & Bienes Inventariados (sólo muebles) & Bienes de Interés Cultural (BIC) \\
\hline Ley 4/1990 de PH de Castilla La Mancha & Bienes integrantes & Bienes Inventariados (sólo muebles) & Bienes de Interés Cultural (BIC) \\
\hline Ley $7 / 1990$ de PC Vasco & No los considera & Bienes Inventariados & Bienes Calificados \\
\hline Ley $1 / 1991$ de PH de la CA de Andalucía & Bienes integrantes & Bienes Catalogados con inscripción genérica & BIC y Bienes Catalogados con inscripción específica \\
\hline Ley 9/1993 del PC Catalán & Bienes integrantes & $\begin{array}{l}\text { Bienes muebles catalogados y } \\
\text { Bienes de Interés local (inmuebles) }\end{array}$ & Bienes Culturales de Interés Nacional \\
\hline Ley 8/1995 del PC de Galicia & No los considera & $\begin{array}{l}\text { Bienes Inventariados } \\
\text { Bienes Catalogados }\end{array}$ & Bienes de Interés Cultural (BIC) \\
\hline Ley 4/1998 de PC Valenciano & Bienes integrantes & Bienes Inventariados & Bienes de Interés Cultural (BIC) \\
\hline Ley $10 / 1998$ de PH de la C de Madrid & Bienes integrantes & Bienes Inventariados & Bienes de Interés Cultural (BIC) \\
\hline Ley $12 / 1998$ del PH de las Illes Balears & Bienes integrantes & Bienes Catalogados & Bienes de Interés Cultural (BIC) \\
\hline Ley $11 / 1998$ de PC de Cantabria & Bienes integrantes & $\begin{array}{l}\text { Bienes Inventariados } \\
\text { Bienes Culturales Catalogados o de Interés Local }\end{array}$ & Bienes de Interés Cultural (BIC) \\
\hline Ley 3/1999 del PC Aragonés & Bienes integrantes & $\begin{array}{l}\text { Bienes Inventariados } \\
\text { Bienes Catalogados }\end{array}$ & Bienes de Interés Cultural (BIC) \\
\hline Ley 4/1999 de PH de Canarias & Bienes integrantes & $\begin{array}{l}\text { Bienes Muebles Inventariados y } \\
\text { Bienes Inmuebles Catalogados }\end{array}$ & Bienes de Interés Cultural (BIC) \\
\hline Ley 2/1999 de PH y C Extremadura & Bienes integrantes & Bienes Inventariados & Bienes de Interés Cultural (BIC) \\
\hline Ley $1 / 2001$ de PC de Asturias & Bienes integrantes & Bienes Inventariados y Catalogados & Bienes de Interés Cultural (BIC) \\
\hline Ley $12 / 2002$ de PC de Castilla y León & Bienes integrantes & Bienes Inventariados & Bienes de Interés Cultural (BIC) \\
\hline
\end{tabular}

Tabla 1

miento de tierras, tanto natural como antrópico, puede destruirlos. $>$ en gran parte es un Patrimonio potencial o posible, ya que todas las normas insisten en que lo es "haya sido o no excavado".

A partir de 1990 las CCAA han ido publicando, en el ejercicio de sus competencias, sus propias normas. En este momento (febrero 2004) las únicas que no lo han hecho son La Rioja, Murcia y Navarra. Contamos por lo tanto con quince documentos legales sobre la materia.

Muy pocas Comunidades han desarrollado sus Reglamentos, pero si han emitido otras normas de menor rango que completan aspectos concretos. Por lo que se refiere al Patrimonio Arqueológico, todas ellas, algunas repetidamente, han publicado regulaciones sobre actividades o intervenciones arqueológicas en las que se establecen las condiciones exigidas para que tales acciones se lleven a cabo, como dice la Ley de Patrimonio Histórico Español, con "garantía de profesionalidad, conveniencia e interés científico".
En síntesis, el análisis de las técnicas jurídicas de protección para los bienes arqueológicos nos indica dos posibilidades de aplicación: las medidas utilizadas para los bienes conocidos, que responden a una gradación acumulable en función de su relevancia, y las que pueden aplicarse al Patrimonio no conocido o presunto, que son exclusivas de los bienes arqueológicos.

\section{Para los bienes conocidos}

Como puede observarse en este cuadro (tabla 1), existe un primer grupo -la primera columna- formado por los bienes integrantes o sin ninguna declaración. Cuenta con un bloque de medidas aplicables a todos los bienes que se consideran parte del Patrimonio Histórico, estén o no inscritos o declarados. Estas medidas son básicas, relacionadas con la conservación del bien. Por lo que respecta al Patrimonio Arqueológico, no están declarados ni inscritos, pero suelen formar parte de listados, relaciones o cartas arqueológicas. Ya desde principios de los 90, Comunidades como la de Castilla-La Mancha pueda probarse su autenticidad. "Esta excepción, afirma la propia Sentencia, ha de interpretarse "en sentido restrictivo, no sólo ya porque asi lo imponen todos los principios que acerca de la conservación de los inmuebles incluidos bajo el ámbito de la Ley se recogen en ésta, sino porque la regla general es la prohibición de la reconstrucción. Así, para esta Sala no puede llegarse a una interpretación amplia que permitiera a través de minimos restos la reconstrucción de un monumento, aun cuando estuviera perfectamente documentado, sino que lo que la ley permite es la reconstrucción de aquellas partes del mismo que pueda realizarse con los materiales originales, y cuya autenticidad exige la ley que se pruebe". En definitiva, en aplicación de la LPHE, "sólo puede reconstruirse cuando se disponga de la mayor parte de los materiales originales, sin perjuicio de que se utilicen materiales ajenos imprescindibles para la estabilidad del monumento".

Esta opción legal en favor de lo que la Sentencia expresamente califica como "minima intervención" se fundamenta también, según señala, en el párrafo 3 del propio artículo 39 en el que se consagra que "las restauraciones de los bienes a que se refiere el presente artículo respetarán las aportaciones de todas las épocas existentes". La obra proyectada, sentenciará, en definitiva, el Tribunal valenciano, "se asienta sobre las ruinas de un teatro romano y las oculta, dejando ver tan sólo a los lados de la cavea dos partes"; constituye, en realidad, "una reconstrucción de un teatro a la manera de los romanos sobre las ruinas del auténtico" por lo que, al margen de la valoración que merezcan los aspectos técnicos o estéticos del Proyecto, debe declararse contrario a los términos del artículo 39.2 de la LPHE.

\section{Los pronunciamientos fundamentales de la Sentencia del Tribunal Supremo de 16 de octubre de 2000}

\section{Introducción}

En el recurso de casación el Ayuntamiento de Sagunto imputa básicamente a la Sentencia recurrida una "aplicación indebida del 


\section{$104-105$ \\ Debate \\ e Investigación \\ La gestión del patrimonio arqueológico en las \\ comunidades autónomas: \\ balance y situación actual \\ PH48 - Abril 2004}

establecen que en los planes urbanísticos de cualquier tipo se incorpore la documentación de estas cartas (Ley 4/1990, art. 20).

El siguiente grupo, Bienes inscritos o declarados sin el máximo nivel, suele consistir en la inclusión del bien en un Inventario o en un Catálogo; es en el que existen mayores diferencias entre Comunidades Autónomas. Una de las razones de este fenómeno es sin duda el hecho de que en la Ley de Patrimonio Histórico Español este nivel sólo incluia a los bienes muebles, por eso, las Comunidades han desarrollado una mayor diversidad para incluir a los inmuebles, trasladando, en la mayoría de los casos, el control sobre ellos a los Ayuntamientos. Así Valencia, en su ley de 1998 ordena que los bienes que hayan sido objeto de catalogación urbanística se incluyan en el Inventario general (Ley 4/1998, Art. 48); algo semejante hace Castilla y León, en su ley de 2002, donde expresa su decisión de que todos los yacimientos arqueológicos protegidos por alguna figura de planeamiento urbanístico, pasen automáticamente a formar parte del Inventario: "Tendrán la consideración de bienes incluidos en el Inventario de Bienes del Patrimonio Cultural de Castilla y León todos aquellos yacimientos arqueológicos recogidos en los catálogos de cualquier figura de planeamiento urbanístico aprobada definitivamente con anterioridad a la publicación de esta Ley, a excepción de los bienes declarados de interés cultural" (Ley 12/2002, Disposición Adicional Segunda).

Los propietarios/as están obligados/as a garantizar su conservación y acceso; se regula y controla su comercio; se establecen los criterios para su restauración. Por lo que respecta a los bienes arqueológicos, en varias normativas se observa cómo la protección real de estos bienes es idéntica a la establecida para los BIC o máxima categoría. Por esa razón la declaración como "inventariado" o "catalogado" o "genérico", denominaciones utilizadas por las distintas normas, podría convertirse en una técnica de protección preventiva tanto para los yacimientos arqueológicos en los que resulte imposible establecer su relevancia antes de ser estudiados, como en aquellos otros que, siendo ya conocidos, no posean las condiciones propias para ser declarados BIC.

El último grupo, los BIC o Bienes de Interés Cultural, constituye el máximo nivel de protección. Sus definiciones insisten en que se trata de "los más relevantes", aquellos que cada Administración ha considerado como dignos del mayor aprecio y las medidas de protección que se les aplican, aunque muy semejante entre sí, varían según la naturaleza del bien -mueble, inmueble, monumental, etnológico, arqueológico, etc.-.

Para esta declaración, las CCAA han creado toda una tipología y terminología bajo la cual han de inscribirse los distintos bienes. En el caso del Patrimonio Arqueológico, la declaración se realiza a través de la figura de Zona Arqueológica. Pero como en algunas normas esta expresión se utiliza también para hacer referencia a yacimientos arqueológicos no inscritos ni declarados, a menudo resulta confusa la interpretación de los textos legales, siendo necesario analizar la práctica concreta de cada administración para comprenderlo.

Las medidas inmediatas, tras la incoación del expediente de BIC, son:

> su declaración de inexportables.

$>$ la paralización de cualquier licencia de obra.

> la adecuación o elaboración del planeamiento urbanístico al cual se sujetará cualquier intervención que deberá ser autorizada.

> en el caso de que haya que realizar una intervención arqueológica la financiará el promotor artículo 39.2 de la Ley de Patrimonio Histórico Español y de la doctrina jurisprudencial relativa a la discrecionalidad técnica de la Administración" pues, se afirma, la Sala de instancia ha "convertido la función de juzgar en función de administrar, sustituyéndose en la aplicación de técnicos y conocimientos propios de la Administración, sin una prueba de contradicción suficiente y razonable". Estas alegaciones, singularmente la primera de ellas, son, en expresión de la propia Sentencia del Tribunal Supremo, las "que atañen a lo que es propiamente el núcleo del debate juridico planteado"; de ahi que sea en ellas en las que debe centrarse nuestra atención.

La interpretación del artículo 39.2 de la LPHE

En términos coincidentes a los ya defendidos por el Tribunal de instancia, la Sentencia del más alto Tribunal sostiene que el citado precepto "impone, como principio, el de evitar los intentos de reconstrucción de los inmuebles históricos de interés cultural. La Ley de 1985 ha optado, pues, por permitir otras operaciones de con- servación, consolidación o rehabilitación que no consistan en la reconstrucción de aquellos inmuebles cuando se encuentren, con palabras clásicas, si un tiempo fuertes, ya desmoronados. En la hipótesis -de suyo excepcional- de que hubiera de procederse a su reconstrucción, ésta ha de llevarse a cabo utilizando precisamente partes originales de probada autenticidad. Todo otro intento de reconstrucción de este género de inmuebles resulta, pues, contrario al artículo 39.2 de la Ley y las propuestas de llevarlo a cabo requeririan una modificación legislativa".

Esta es, dice el Tribunal Supremo, "la interpretación del precepto legal que se infiere, sin excesivos problemas hermenéuticos, del sentido propio de los términos en él utilizados, puestos en relación con su contexto, y que coincide con la deducible de los antecedentes legislativos y del debate parlamentario en que fue aprobado", debate, en efecto, extremadamente ilustrativo y del que la propia Sentencia da cumplida cuenta. Con este fundamento se confirma la Sentencia recurrida y se declara, por consi- 
La única Comunidad que desarrolla un sistema de declaración diferente es el País Vasco, que establece tres figuras: Monumento, Conjunto Monumental y Espacio Cultural, con independencia de la naturaleza mueble, inmueble, etnológico, arqueológico, etc. del bien, así como con independencia de su grado de declaración.

\section{Para los Bienes no conocidos o presuntos}

El conjunto de técnicas destinadas a la protección de los bienes arqueológicos cuya existencia se presume, es el más original y propio del Patrimonio Arqueológico.

La Ley de Patrimonio Histórico Español tuvo en cuenta la posibilidad de proteger los terrenos en los que se presumiera la existencia de bienes arqueológicos (Art. 43) y las Comunidades Autónomas, a partir de ahí, han ido mejorando esa escueta posibilidad, incluso con la creación de figuras específicas.

En realidad, las medidas destinadas a proteger el Patrimonio Arqueológico posible podrían a su vez separarse en dos: por un lado, aquellas en las que lo que se protege son terrenos concretos en los que, por indicios o por cualquier otra causa, se sabe o se sospecha la existencia de bienes arqueológicos; esos terrenos incluso pueden estar delimitados y ser objeto de inscripciones, como los casos de Andalucía y Cataluña, o ser considerados BIC, como en Extremadura.

Por otro lado, aquellas en las que lo que se protege es el Patrimonio Arqueológico cuya existencia ni siquiera se sospecha, ese que puede estar enterrado en cualquier lugar y que puede salir en cualquier momento, durante una obra o movimiento de tierras. Para este tan sólo existen por ahora dos medios legales de protección: su consideración en las evaluaciones de impacto am- biental o la paralización de la obra ante la aparición de restos. En este último caso existe una desarrollada regulación en el articulado titulado "Hallazgos casuales" (Querol y Martínez 1996, 1998 y 2001).

En el siguiente cuadro (tabla 2) se ha introducido las figuras y los regímenes de protección. En primer lugar, las de máxima protección para los bienes arqueológicos inmuebles. Después, las figuras pensadas para proteger, a veces como BIC, a veces como bien Inventariado e incluso a veces sin especificar el sistema, aquellos lugares en los que se sospecha fundadamente la existencia de restos arqueológicos.

En todas estas figuras destinadas a la protección de los lugares en los que se presume la existencia de restos arqueológicos, las Comunidades Autónomas han ido añadiendo toda una serie de condiciones en las que tal protección se funda. Al igual que ocurre con los bienes inventariados o incluso declarados, se establece como necesario un estudio de la incidencia de las posibles obras sobre los restos, estudio cuya financiación, por lo general, se atribuye al promotor/a (p.e. en la Ley 3/1999 de PC de Aragón, Art. 68.2.b).

Por lo que respecta a la declaración o consideración de "Zonas de reserva arqueológica" que, como vimos, está recomendada por los documentos internacionales más modernos sobre protección del PA, pocas leyes la han introducido en su articulado. Destaca la de la Comunidad Valenciana (Ley 4/1998) que la incluye como figura de declaración y que la considera en todo caso una parte no excavada de un yacimiento declarado BIC. También Castilla y León (Ley 12/2002, Art. 55.4) habla de que en la autorización de excavaciones arqueológicas se establecerán zonas de reserva que permitan realizar estudios posteriores. Dado el in- guiente, la falta de conformidad a Derecho de un Proyecto cuya bondad desde el punto de vista técnico y artístico no se discute, pero que es sencillamente contrario a los términos de la LPHE, como resulta del análisis del propio expediente administrativo y de las pruebas practicadas en el proceso seguido ante el Tribunal Superior de Justicia de Valencia.

En conclusión, la reconstrucción de bienes inmuebles del Patrimonio Histórico constituye con carácter general una operación prohibida a menos que "se utilicen partes originales de los mismos y pueda probarse su autenticidad". Solo excepcionalmente se podrán añadir "materiales o partes indispensables para su estabilidad o mantenimiento" que deberán ser, en todo caso, reconocibles.

\section{El alcance de la discrecionalidad técnica en el ámbito del} Patrimonio histórico

La respuesta al segundo de los grandes reparos opuestos por el Ayuntamiento de Sagunto a la Sentencia del Tribunal Superior de
Justicia de Valencia: la presunta invasión por el Tribunal de las funciones propias de la Administración en un sector de la actividad estrechamente dependiente del juicio técnico procedente de las mas diversas ramas del saber, es resuelto por la Sentencia comentada con la misma claridad que brevedad. La objeción no es aceptable, dice, porque "baste decir que cuando una de las soluciones que tratan de ampararse bajo la cobertura de la discrecionalidad no resulta jurídicamente indiferente, sino contraria a una norma con rango de ley -como aquí ocurre-, la Sentencia de un Tribunal que así lo declara no invade competencia administrativa alguna, antes bien ejercita la función que constitucionalmente le está atribuida, esto es, la de controlar que la actividad de la Administración se atenga a los mandatos legislativos". Cuestión distinta es que "el Legislador hubiera dejado imprejuzgados los criterios que han de regir la reconstrucción de este genero de inmuebles", en cuyo caso la Administración sí que estaria legitimada para "elegir libremente entre las diversas alternativas propuestas, sin que el núcleo de su decisión discrecional pudiera ser suplido por la apreciación distin- 


\section{$106-107$ \\ Debate e Investigación \\ La gestión del patrimonio arqueológico en las comunidades autónomas: balance y situación actual \\ PH48 - Abril 2004}

terés de este punto -los yacimientos arqueológicos de nuestro país son numerosos, pero no infinitos- algunas administraciones han publicado proyectos en los que se apunta y se desarrolla la necesidad de guardar para el futuro bienes arqueológicos sin tocar. Es el caso del País Vasco, que defiende tal necesidad en la obra "Avance del Plan territorial sectorial del Patrimonio Cultural Vasco" (Avance, 2000).

\section{La regulación de la actividad arqueológica}

Este es un tema muy desarrollado tradicionalmente en nuestra legislación, quizá porque la Universidad no ha resuelto todavía la existencia de una titulación de Arqueología o por la inexistencia de un Estatuto Profesional reconocido. Desde la Ley de 1911 hasta hoy, el control sobre quiénes van a recibir una autorización de intervención arqueológica y cómo va a realizarla, qué tiene que entregar, dónde y cómo, ha seguido un camino propio, exclusivo y exhaustivo para este Patrimonio.

El conjunto de su tratamiento tenemos que buscarlo tanto en las leyes como en otras normas de inferior rango, emitidas con distinta regularidad por las Comunidades Autónomas. La Administración General del Estado no ha publicado nada en este aspecto.

En líneas generales las medidas consideradas en las normas son las siguientes:

> necesidad de una autorización expresa de la Administración competente para las actividades que cada territorio determina.

$>$ condiciones sobre quiénes podrán solicitar estas autorizaciones. $>$ los requisitos, obligaciones y procedimientos derivados del otorgamiento de la autorización.
> ejercicio de inspección y control del desarrollo de las actividades. $>$ sobre la entrega de los materiales obtenidos.

Sin embargo en los textos que regulan las actividades e intervenciones, la principal aportación que realizan las normas de las Comunidades es la ampliación de los tipos de actividades que se someten a regulación. En el siguiente cuadro podemos ver algunos ejemplos de ello (tabla 3).

Aquí hemos incluido desde la Ley de Patrimonio Histórico Español, con tan sólo excavaciones y prospecciones, a la ampliación de estos tipos que hace Canarias, Ilamándolas Intervenciones; o la aparición de la distinción que marcan Baleares o Aragón con las intervenciones de urgencia, para finalizar con la que consideramos más completa de las propuestas hasta ahora, la de Cantabria. Bajo el epigrafe de Actuaciones Arqueológicas (término genérico, incluye las actividades que no afectan a la materialidad del Patrimonio y las intervenciones que sí afectan) esta Comunidad distingue tres tipos: Carácter preventivo, de investigación o de salvamento (Ley 11/1998, Art. 76).

\section{Consideraciones}

Han pasado más de veinte años desde las trasferencias de las competencias sobre el Patrimonio Arqueológico de sus territorios a las Comunidades Autónomas y nos encontramos en un momento excepcional: hace pocos años no hubiéramos podido hablar de mecanismos legales más allá de la exigencia de una autorización para hacer excavaciones, mientras que ahora no sólo encontramos diferentes niveles de protección, sino que incluso podemos desarrollar toda una serie de iniciativas para la prevención ante los bienes que no se conocen o aquellos cuya existencia se sospecha. ta de un Tribunal de justicia que se basara en sus particulares criterios acerca de los valores estéticos, artísticos o monumentales".

La tesis suscrita por la Sentencia debe ser justamente ponderada. Y no porque sea discutible -mantiene la posición juridicamente correcta-, sino porque viene en alguna medida a enmendar la propia posición sustentada por el Tribunal Supremo en Sentencias, por ejemplo, de 22 de junio o 20 de julio de 1998 en las que, en el ámbito también del Patrimonio Histórico, se considera que las resoluciones fundadas en los informes emitidos por órganos especializados durante la tramitación del procedimiento administrativo están amparadas por una presunción de certeza o razonabilidad apoyada en la especialización e imparcialidad de los órganos encargados de informar que llega a modular, incluso, la plenitud del control jurisdiccional. Las dificultades que indudablemente, en estos casos, presenta la determinación de la solución juridicamente correcta no puede, sin embargo, llevar a la defensa de una solución que, de hecho, excluya determinadas decisiones adminis- trativas del control de los Tribunales bajo esa supuesta "presunción de certeza o de razonabilidad de la actuación administrativa".

Reflexión final: El valor de una Sentencia de importancia capital. Los innegables problemas que presenta su ejecución

La STS de 16 de octubre de 2000 posee una significación verdaderamente capital para la interpretación y aplicación del régimen de protección del Patrimonio Histórico. Y no sólo porque determina el preciso sentido de un precepto fundamental para la conservación, el artículo 39 de la LPHE, sino porque saca también a la luz ideas y principios de importancia fundamental en la correcta aplicación de este orden normativo. Con esta Sentencia el Tribunal Supremo cierra, en otros términos, la puerta a actuaciones sobre bienes culturales que, con independencia del juicio que puedan merecer desde un punto de vista técnico o artístico, no atiendan a los rigurosos límites con los que la Ley de 1985, como ya lo hacia su predecesora la 


\section{Ley 16/85 del PH Español \\ Ley 4/1990 de PH de Castilla La Mancha \\ Ley 7/1990 de PC Vasco \\ Ley $1 / 1991$ de PH de la CA de Andalucía \\ Ley 9/1993 del PC Catalán \\ Ley 8/1995 del PC de Galicia \\ Ley 4/1998 de PC Valenciano \\ Ley 10/1998 de PH de la C de Madrid \\ Ley 12/1998 del PH de las Illes Balears \\ Ley 11/1998 de PC de Cantabria}

Ley 3/1999 del PC Aragonés

Ley 4/1999 de PH de Canarias

Ley 2/1999 de PH y C Extremadura

Ley $1 / 2001$ de PC de Asturias

Ley 12/2002 de PC de Castilla y León
Zona Arqueológica (Art. 15.5)

Zona Arqueológica (Art. 15.5 LPHE)

Parque Arqueológico

Zona Arqueológica

Parque Arqueológico

Zona Arqueológica (Art. 27)

Zona Arqueológica (Art. 7.2.f)

Zona Arqueológica (Art. 48)

Zona Arqueológica (Art. 26.1.A.e) Areas de reserva arqueológica (Art. 66)

Zona Arqueológica (Art. 9.2.e)

Zona Arqueológica (Art. 6.6)

Yacimiento Arqueológico (Art. 89.1,a) Zona Arqueológica (Art. 89.1,b)

Parque Arqueológico (Art. 89. 1,C)

Zona Arqueológica (Art. 12.2.B.e)

Zonas de Protección Arqueológica (Art. 67)

Zona Arqueológica (Art. 18.1,e)

Parque Arqueológico (Art. 63)

Zona Arqueológica (Art. 6.1,e)

Parque Arqueológico (Art. 6.1,h)

Zona Arqueológica (Art. 11.1.e)

Zona Arqueológica (Art. 8.3,e)
Zonas de Servidumbre Arqueológicas (Art. 48.1)

Espacios de Protección Arqueológica (Art. 49.1)

No se especifica

No se especifica

Áreas de protección Arqueológica (Art. 89.1,d)

No se especifica

Espacios de interés Arqueológico (Art. 58.1)

Declaración como BIC

Área de protección Arqueológica (Art. 89.1,d)

Inclusión en el Inventario

Zona de Prevención Arqueológica (Art. 68)

No se especifica

Espacios de protección Arqueológica (Art. 6.1,i)

$\mathrm{BIC}$

Espacios Arqueológicos (Art. 65)

No se especifica

Yacimiento Arqueológico Inventariado (Art. 17.3,c)

Como bien Inventariado

Tabla 2

Es evidente que en cada ocasión, las Comunidades Autónomas, al ir publicando sus leyes, se han esforzado por perfeccionar o adecuar los procedimientos de protección, incluyendo toda una serie de novedades, de las que hemos analizado algunas.

Sin embargo, la experiencia en la gestión de los bienes arqueológicos de todos estos años nos indica la necesidad de importantes cambios tanto en el tratamiento legal como en el real de estos bienes. En palabras de Rodriguez Temiño: " ...hay que gestionar la demanda de excavaciones arqueológicas, retroalimentando negativamente el sistema mediante disposiciones en el planeamiento urbanístico" (Rodríguez Temiño 2004:370).

Uno de los cambios que consideramos necesarios tiene que ver con el hecho de que las intervenciones arqueológicas que se realizan en nuestros territorios se ajustan mucho más a los imperativos del crecimiento urbano y de las transformaciones rurales que a verdaderos programas de ampliación del conocimiento histórico. $Y$ ya que la Arqueología es ante todo investigación histórica, esto provoca un desajuste que queda reflejado, principalmente, en el escaso conocimiento que llega a la sociedad sobre su pasado. En definitiva, se excava ahora mucho más que antes, pero, en proporción, se conoce menos.

Por otra parte hay que conseguir que la documentación arqueológica previa a la aprobación de los proyectos de obra sea suficientemente detallada como para lograr que se produzca su protección adecuada antes de que se generen expectativas de lucro sobre la explotación urbana del suelo que ocupa.

Tanto estas ideas, como muchas otras que podríamos añadir, resultan difíciles en la práctica diaria de la gestión de unos bienes
Ley de 13 de mayo de 1933, se alinea con lo que la propia Sentencia de instancia califica de "intervención mínima" en una clara decantación por el mantenimiento del estado en el que el monumento ha llegado hasta nosotros y consiguiente rechazo de aquellas otras teorias partidarias de una actuación sobre el inmueble que lo devuelva a su primitivo origen. Es importante señalar, además, que el Tribunal Supremo ha sostenido posteriormente esta misma interpretación en los contenciosos sobre la legalidad de la intervención en el conjunto histórico de Tossa de Mar (Sentencia del Tribunal Supremo de 22 de marzo de 2002) y el proyecto de ampliación del Museo Nacional del Prado (Sentencia del Tribunal Supremo de 18 de diciembre de 2002).

Desestimado el recurso de casación interpuesto contra la Sentencia del Tribunal Superior de Justicia de Valencia procede su ejecución definitiva; el interrogante está servido ¿es posible jurídica y materialmente dicha ejecución?; ¿cómo se puede llevar a puro y debido efecto la anulación del Proyecto de Restauración y Rehabilitación del Teatro Saguntino?

Es claro que el tema excede del escaso espacio del que disponemos. Puede, no obstante, apuntarse que conforme a la regulación de la ejecución de sentencias firmes de la Ley de la Jurisdicción ContenciosoAdministrativa de 1998 parece que no concurren en este supuesto causas de imposibilidad material o juridica que impidan el debido cumplimiento del fallo. El problema es cómo llevar a efecto la demolición de las partes reconstruidas, devolviendo el teatro a su estado originario, anterior a la ejecución de la obra pública anulada. La dificultad de la fase de ejecución se suscita pues, no desde la perspectiva procesal, sino desde las limitaciones derivadas de una nueva y compleja intervención sobre un bien de interés cultural. No obstante, esta dificultad puede verse al menos parcialmente superada, en la medida en que como se desprende del expediente administrativo, las adiciones proyectadas y parcialmente ejecutadas eran reconocibles, para evitar, en cumplimiento de la LPHE, "confusiones miméticas". 